\title{
Exploration in Applied Talents Training Mode Innovation of the New Undergraduate Colleges Based on the "R\&O-CPIO 3+1" Mode
}

\author{
Gui-hua YU* \\ Wenzhou Business College, Wenzhou 325035, China \\ * Corresponding author
}

Keywords: Specialty Construction; "CPIO" Mode; Curriculum System; Teaching Mode; Depth Cooperation between Colleges and Enterprises.

Abstract. In order to improve the quality of personnel training, it is necessary to reform the teaching mode. Taking e-commerce as an example, this paper uses qualitative research method and empirical research method to construct the "R\&O-CPIO 3+1" personnel training mode, and designs the operation mechanism and implementation scheme, which has achieved great results in practice and is feasible.

\section{Analysis of Personnel Training Mode of "R\&O CPIO 3+1"}

A large-scale in-depth professional survey was conducted, the main research objects were brothers' colleges and universities, e-commerce associations, small and medium-sized enterprises in network marketing. In the form of questionnaire, telephone interview, network consultation and small-scale research exchanges, according to the specialty investigation and the characteristics of e-commerce specialty, reforms the existing talent cultivation mode, stresses the application-oriented talent cultivation characteristics of "quick start and strong foot", and explores the innovative talent cultivation mode reform plan of "R\&O-CPIO $3+1 "$.

This mode explores the orientation of talent cultivation of "the integration of professional foundation, practical ability and humanistic accomplishment". It cooperates deeply with enterprises to formulate training objectives, construct curriculum system and teaching content, implement training process and evaluate training quality, so as to provide students with practical opportunities and places. The Real \& Open CPIO $3+1$ mode participate in teaching from enrollment to graduation enterprises ${ }^{[1]}$.

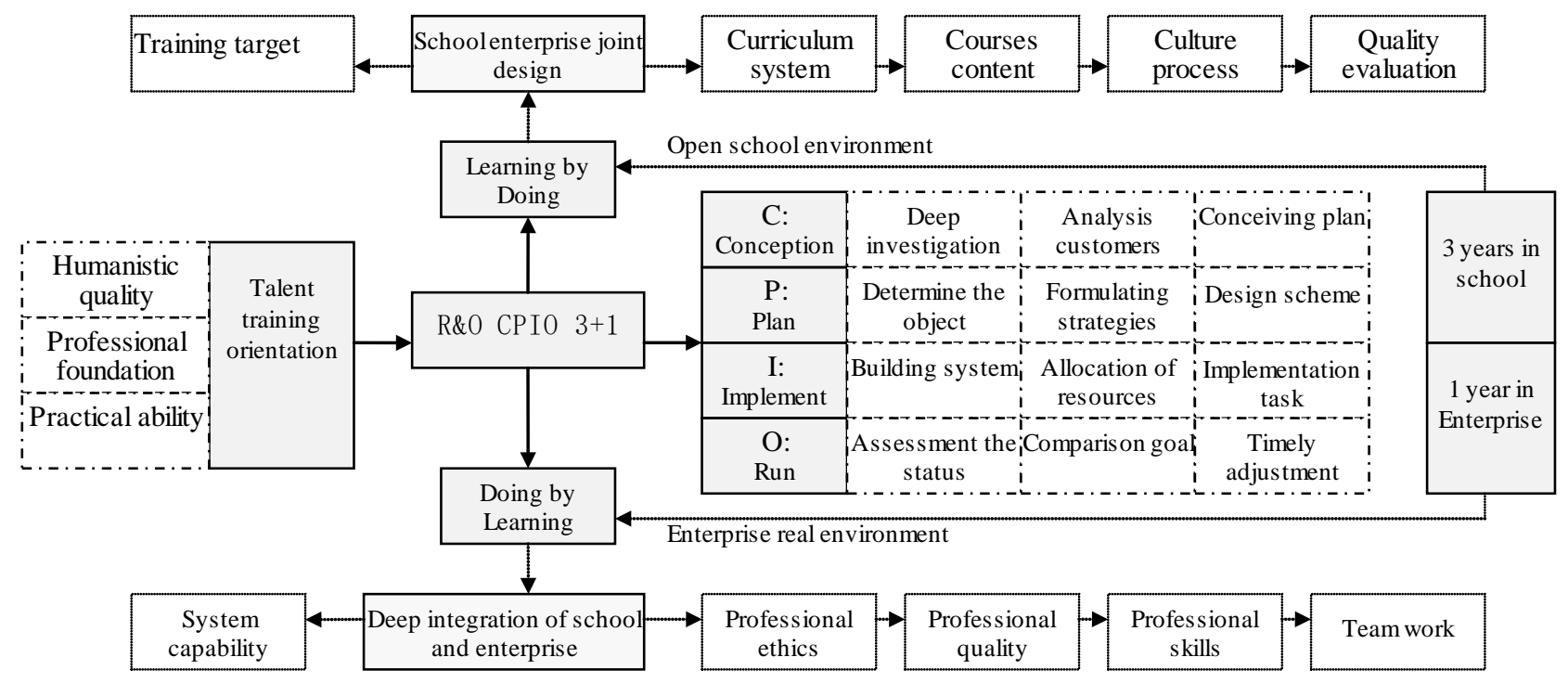

Fig. 1 E-commerce Specialty "Real \& Open-CPIO 3+1 Mode”

"R\&O CPIO 3+1 mode" accords with CPIO education concept in a real and open environment, Among them, $\mathrm{C}$ is the conceive -in-depth investigation, environment analysis, customers analysis , conceptual 
programs; $\mathrm{P}$ is the planning - to determine objectives, clear objects, formulate strategies, design solutions; I is the implementation - to organize teams, build systems, allocate resources, implement tasks; $\mathrm{O}$ is the operation-Assessment of the status quo, comparative objectives, analysis of causes, timely adjustment. "3 + 1" means three years in school, and one year in the enterprise personnel training (see Fig. 1 for details).

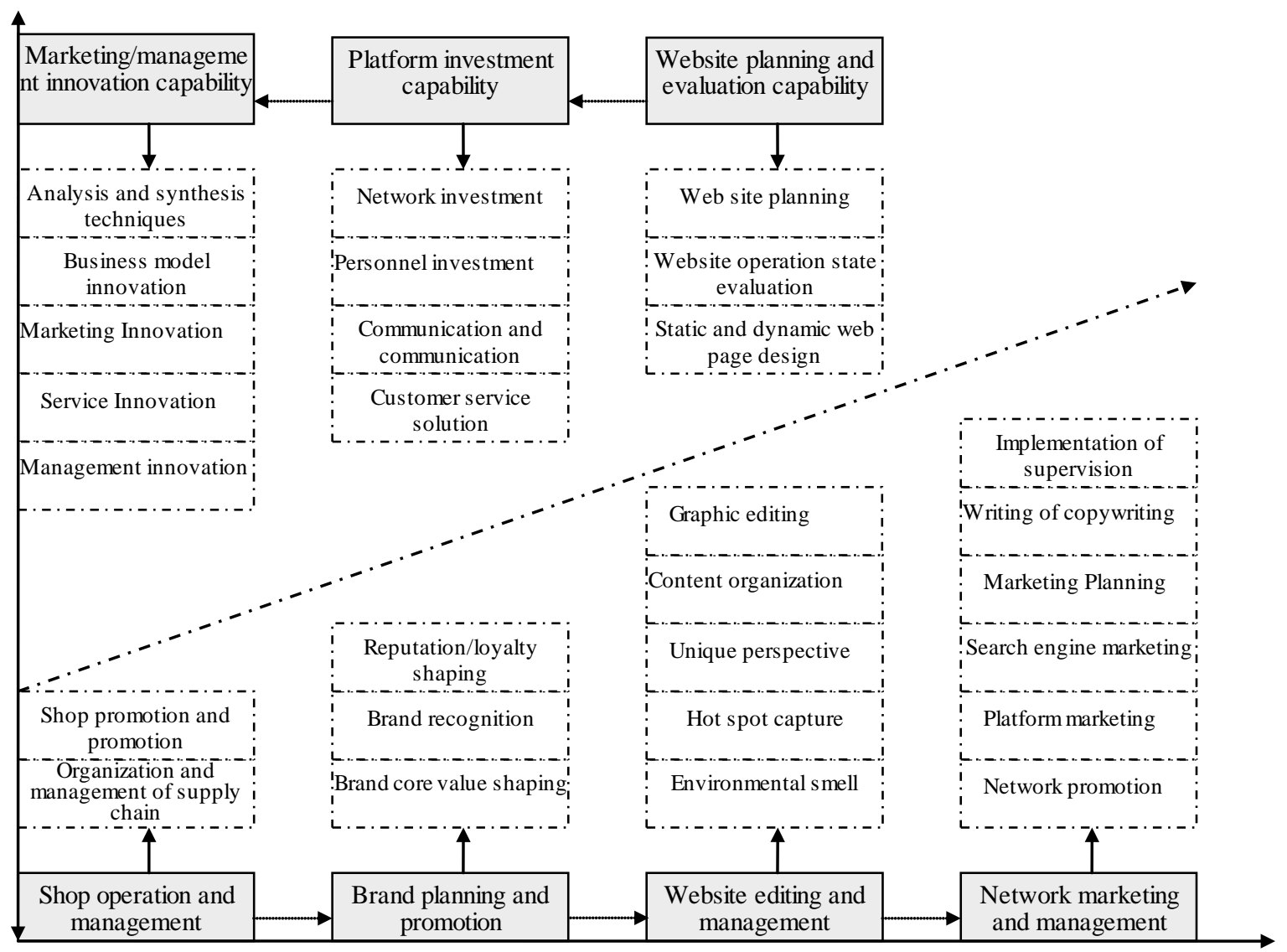

Fig. 2 Capability structure diagram of "Real \& Open-CPIO 3+1 Mode”

The core of this model is to take the whole life cycle of marketing activities (C-P-I-O) as the carrier, to cultivate the students' four levels of abilities: basic knowledge, professional skills, team ability and system ability, to build a "real and open" base for the environment, and to take the real network marketing task as the inside, "doing middle school, learning in the middle, learning while doing, learning while doing" conducts e-commerce talents training. An important component of the "R\&O CPIO 3+1" model is to enable students to engage in practical work related to their own profession in enterprises, and successfully complete the "three transformations of professional ethics, professional quality and professional skills" and the smooth transformation from students to qualified workers ${ }^{[2]}$. The core skills training directions of R\&O CPIO 3+1 model for e-commerce major are: online store management and management ability, brand planning and promotion ability, website editing and management ability, network marketing and management ability, website planning and evaluation ability, platform investment ability, marketing and management innovation ability (specific ability structure see Fig. 2).

\section{The Reform Path of E-commerce Specialty Based on "R\&O CPIO 3+1" Mode}

\subsection{Re orientation of professional reform objectives}

The specialty reform goal of "R\&O CPIO 3+1" mode is: School-School cooperation, school-enterprise cooperation, joint participation, research and exchange, promote the cultivation of network marketing application talents, promote the development of e-commerce application in small and medium-sized enterprises, make the personnel training mode, curriculum system, teachers team more perfect, and practice 
experimental conditions more complete. To promote the popularization of e-commerce, promote the development of local cross-border e-commerce industry, so as to better serve the community and the local economy.

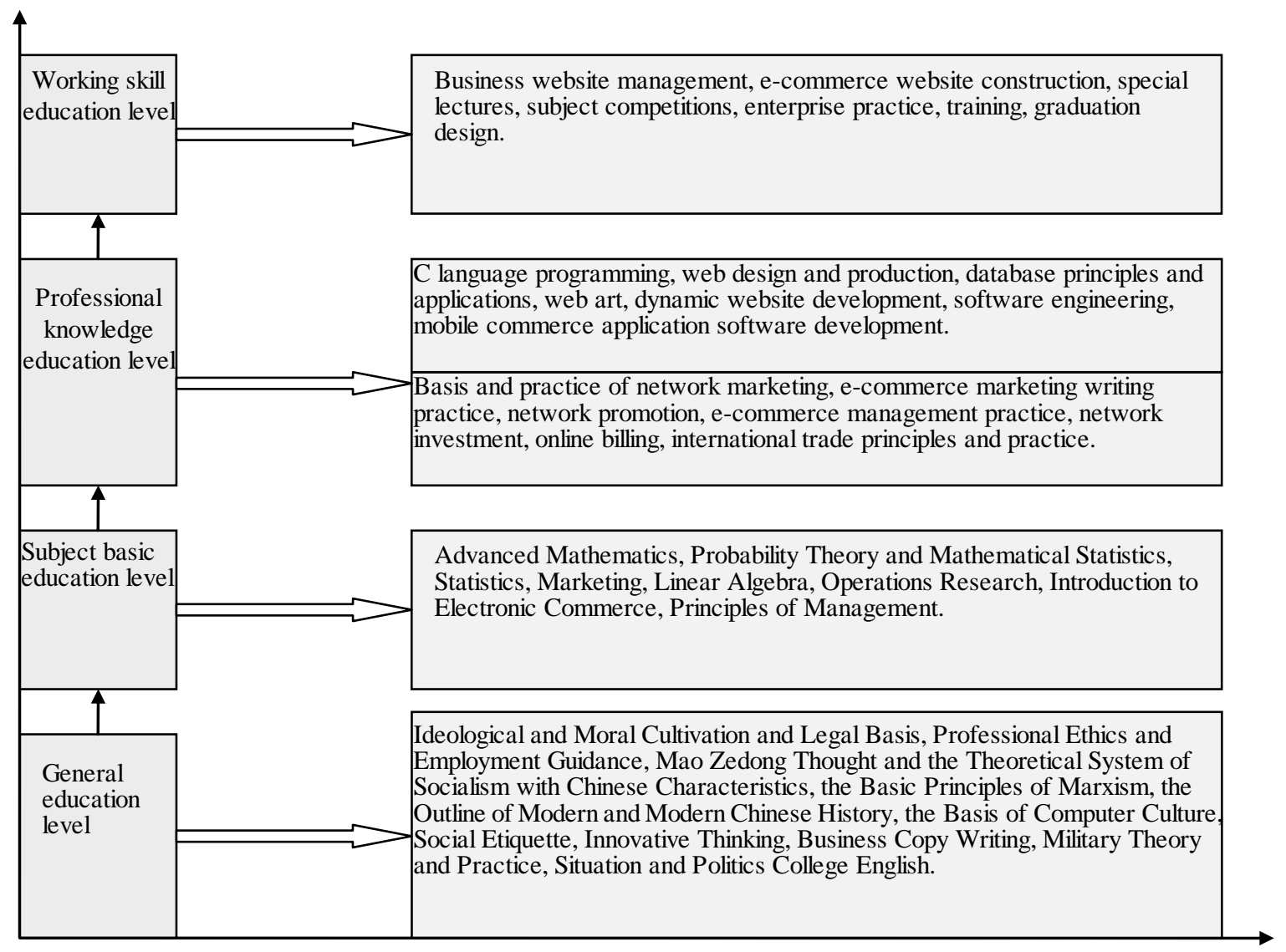

Fig. 3 Setting up curriculum system of E-commerce Specialty

\subsection{Curriculum system reform}

The reform of the curriculum system is guided by the needs of the enterprises and centered on the cultivation of students' engineering practice ability and innovative ability. The curriculum system is divided into four levels: general education, subject basic education, professional knowledge education and work skill education ${ }^{[3]}$. Gradually and systematically cultivate and enhance the students' website planning from shallow to deep. With the evaluation ability, marketing and management innovation ability, website editing and management ability, network marketing and management ability, platform investment and customer service ability, online store management and management ability, brand planning and promotion ability and professional quality.

\subsection{Construction of practical teaching system}

\subsubsection{Strengthening existing training projects}

E-commerce majors begin their internship as "web editor" directly in the positions of web editor, information column administrator, forum moderator, blogger, digital column administrator, among which the better ones will assume the roles of deputy director, column supervisor, channel (or integrated section) deputy director and master, until the work of deputy director and supervisor of base website. Strengthen the training of "service websites (such as information), business transaction websites (such as online shops), trading platform websites (such as platform customer service and investment promotion), virtual community websites (such as forums, blogs) and take their actual websites as the object of participating in various marketing planning and implementation, Single, investment promotion, network promotion and other practical training ${ }^{[4]}$. 


\subsubsection{Enhancing the effectiveness of training bases for personnel training}

At present, the college's e-commerce training base group consists of JF2006 e-commerce skills training base, China Green Health Care Network, Green Health Care Brand Network, E-commerce Association, New Asia Beauty Network, Wuzhou Source Taobao Flagship Store and other platforms. These platforms have become trainees to carry out marketing innovation, brand marketing, network platform. Marketing, search engine marketing and network marketing base. Develop website promotion services, product promotion services, and brand promotion services to carry out services for students to provide a complete "real, open" training task. In order to enable students to understand the latest knowledge of network marketing and master the skills of network marketing, the College and Hand in Hand-in-Hand Network, Ali College of Alibaba Group, Taobao Network, Baidu Information Technology (Beijing) Co., Ltd., Jingdong Mall and other enterprises to get in touch, by the enterprise specially allocated tasks for our students to exercise the students' actual situation practical ability. At present, our school has become a cooperative group of Alibaba group. Some students have become the campus executive officer of Alibaba Group, the head of the campus shopping agency of Jingdong Mall, and the head of the University hand in hand.

2.3.3 Develop new network marketing system and expand training space

Develop the "network marketing service and supervision system", set up the network marketing pusher supervision system, hot topic arrangement and release management system, brand promotion plan management system, brand diagnosis online investigation management system, customer tracking and planning supervision system, basic database construction and management system, network marketing order management system Systems and so on, in the website construction, the network marketing, the website management, the ability training and so on thorough development, unceasingly develops the new network marketing system.

\subsection{Teaching mode reform}

\subsubsection{Four step teaching method}

The four-step teaching method integrates the four links of "teaching, discussion, practice and stimulating innovation" into the teaching process. The typical teaching process follows the sequence of "game-teaching-discussion-practice", but it is not "rigid, rigid, fixed and unchanged".

(1) Game: In view of the actual problems of base operation, let students' unrestrained "fantasy" to deepen the "innovative consciousness" and cultivate innovative ability;

(2) Teaching: striving to grasp the key points and difficulties, carry out teaching in a small and precise way, and emphasize the cultivation of students' self-learning ability.

(3) Seminar: Interactive questioning and discussion can not only deepen teaching, but also cultivate students' ability of oral expression, communication and communication.

(4) Practice: According to the arrangement of the implementation plan of "Four Level Standard Achievement", the time ratio between teaching and practice is $1: 1$, which aims to make students "open-minded, active, innovative and practical". This method strives to adhere to the principle of "heuristic" and "less and more refined", and puts the focus of teaching on training students' practical ability and innovative ability.

\subsubsection{Case teaching reform}

By means of physical teaching, demonstration teaching, on-the-spot teaching, online marketing practice teaching and so on, we can make the teaching more practical and effective in form and content. According to the needs of the development of e-commerce in enterprises, the cultivation of e-commerce application talents with marketing skills as the main training direction at present is to cultivate six kinds of subjective consciousness, namely, commercial consciousness, practical consciousness, innovative consciousness, brand consciousness, team consciousness and system consciousness, and seven kinds of core skills: "website planning and Evaluation ability, marketing and management innovation ability, website editing and management ability, network marketing and management ability, platform investment and customer service ability, online store management and management ability, brand planning and promotion ability. The teaching contents of these courses are based on the "real and open" environment. They are used in business courses, such as "Marketing Innovation", "Business Website Management", "Business Platform Investment 
Promotion", "Hot Topic Planning, Organization and Implementation", "Practical Network Promotion" and "Brand Strategic Planning and Promotion". Enterprise marketing case teaching, case into the classroom, case into the experimental base, to train students' ability to analyze and solve problems, according to the CPIO ideas, put forward problems, formulate plans, implement plans, summarize the gains and losses, carry out enterprise-style assessment, according to performance assessment, improve practical operation skills.

\subsubsection{Role conversion Teaching}

We should adopt flexible and varied curriculum and teaching methods, integrating "teaching, learning and doing" into one. According to the content of the course and the characteristics of the students, we should formulate learning objectives, conduct learning guidance, classroom discussion, and carry out learning evaluation, so as to give full play to the students'subjective initiative, encourage students to actively make interactive speeches and questions in the classroom. Teachers and students can participate in classroom teaching together, in the form of group discussion and teachers, student research, case analysis, demonstration and guidance, etc., to promote students' autonomous learning and improve the quality of classroom teaching. E-commerce network marketing involves many posts, such as web page editing, image processing, column manager, website manager, project marketing director and so on. In practice, we divide students into several groups, assume the corresponding roles, assume the role responsibility, complete the role task, and exercise the corresponding ability, after a certain period of time. After that, roles are rotated and played different roles, so that they can be trained in all positions. At the same time, they actively participated in various professional skills competitions, such as the "Tomorrow Internet Business" Challenge Competition for Chinese College Students organized by Alibaba Group, the "Win the Campus" Internet Marketing Skills Competition, and the "Emotion E Township, National College Students'Rural Informatization Competition" organized by Baidu.

\section{Summary}

Therefore, our college actively seizes this reform opportunity, strengthens the school teaching basic construction unceasingly, the teaching reform unceasingly thoroughly, has formed "trains adapts to the region economy social construction demand, the knowledge ability quality coordinated development application technical talented person" the training characteristic. In order to adapt to the orientation of this new talent cultivation mode and to meet the needs of local economic development, E-commerce specialty has been constantly exploring and practicing, and has put forward the "R\&O-CPIO 3+1" talent cultivation mode. Since the implementation of this mode, with the strong support of the college, we have actively carried out the discipline construction, carried out the training mode research, the curriculum system research, the construction of high-quality courses, the construction of characteristic specialties and other work. With the curriculum practice, we should make use of the real and open e-commerce environment to carry out the practical Research of teaching reform and train students. Taking the market as the guide and serving as the purpose, the training mode of skilled, compound, innovative and enterprising talents is explored, so that the trained students can learn better and obtain employment smoothly. The one-off employment rate in the past five years has remained above $98 \%$. This study attempts to further sort out and analyze this new model, sum up experience, to provide experience for the construction of new undergraduate colleges and universities.

\section{Acknowledgment}

This study is particularly grateful to the following two units, the project of Wenzhou Business college teaching reform "Introducing group counseling method to improve the teaching effect of Ideological and Political Theory Course", and Zhejiang Province, 13th Five-Year, the first batch of teaching reform projects "using activity teaching method to improve the teaching effect of Ideological and Political Theory Course".

\section{Reference}

[1]. Cai X F, Li N. Discussion on the teaching mode of higher vocational nursing specialty based on CDIO model[J].Global Journal of Nursing Research,2013,1(1):5-8. 
[2]. Chen X, Qiu Y. The Reform for Software Engineering Majors Based on CDIO[J].Applied Mechanics \& Materials,2013,380-384:2464-2467.

[3]. Fan Y, Zhang X, Xie X. Design and Development of a Course in Professionalism and Ethics for CDIO Curriculum in China[J].Science \& Engineering Ethics,2015,21(5):1381-1389.

[4]. Chuchalin A, Malmqvist J, Tayurskaya M. Professional development of Russian HEIs'management and faculty in CDIO standards application[J].European Journal of Engineering Education,2016,41(4): 426-437. 